\title{
Parent Perceptions of the Value of Pediatric Neurology Clinic Visits
}

\author{
J.M. Dooley, K.E. Gordon, E.P. Wood
}

\begin{abstract}
Background: There is little data available on the acceptability to parents, of alternate methods of delivering care to their children. This pilot study explored parents'perceptions of conventional clinic visits and their attitudes to potential alternative methods of delivering care. Methods: Questionnaires were completed by the families of 200 consecutive children before and after a visit to a tertiary-care Pediatric Neurology Clinic in Nova Scotia, Canada. Results: Responses were received from 172 (86\%) for the first questionnaire and $138(69 \%)$ for the second. There were 59 new referrals, 76 follow-up visits and 39 were seen because of new concerns. Visiting the clinic resulted in school absenteeism for $85 \%$ of the children and lost pay for $19 \%$ of the parents. Telephone, video conference or replacement of the physician by a nurse practitioner were acceptable alternate methods of assessment for only $10 \%$. The only factor which was associated with willingness to accept telephone as an assessment modality was an initial opinion that the visit was unnecessary. Conclusion: Escalating health care costs and limited specialist availability demand consideration of alternate methods of care delivery. Although adults seem comfortable with care outside the usual clinic setting, there is little data for the pediatric setting. The responses from the parents attending our clinic, indicate that families were happy with services offered in the conventional clinic. In contrast, only $10 \%$ found potential alternate methods acceptable. These opinions must be considered in the design of new methods of caring for children.
\end{abstract}

RÉSUMÉ: La perception des parents au sujet de l'utilité des visites à la clinique de neurologie pédiatrique. Introduction: Il y a peu de données disponibles sur l'acceptabilité par les parents de méthodes alternatives de fournir des soins à leurs enfants. Cette étude pilote explore les perceptions des parents au sujet des visites cliniques conventionnelles et leurs attitudes au sujet de méthodes alternatives potentielles de fournir des soins. Méthodes: Des questionnaires ont été complétés par les familles de 200 enfants consécutifs avant et après une visite à une clinique de neurologie pédiatrique de troisième ligne en Nouvelle-Écosse, au Canada. Résultats: On a reçu 172 (86\%) réponses au premier questionnaire et 138 (69\%) au deuxième. Il s'agissait d'une première consultation pour 59 patients, d'une visite de suivi pour 76 patients et d'une visite motivée par l'apparition de nouveaux symptômes pour 37 patients. La visite à la clinique impliquait une absence scolaire pour $85 \%$ des enfants et une perte salariale pour $19 \%$ des parents. Un appel téléphonique, une vidéo conférence ou une consultation avec une infirmière clinique étaient des méthodes d'évaluation alternatives acceptables chez seulement $10 \%$ des cas. Le seul facteur qui était associé à l'acceptation du téléphone comme mode d'évaluation était une opinion initiale que la visite n'était pas nécessaire. Conclusions: On doit considérer des méthodes alternatives de fournir des soins de santé vu l'accroissement des coûts de santé et la disponibilité limitée de spécialistes. Bien que les adultes semblent confortables avec les soins prodigués hors des cadres cliniques habituels, il existe peu de données sur la situation en pédiatrie. Les réponses des parents qui fréquentent notre clinique indique que les familles étaient satisfaites des services offerts par une clinique conventionnelle. Par contre, seulement $10 \%$ considéraient que d'autres méthodes étaient acceptables. Ces opinions doivent être considérées dans la planification de nouvelles méthodes de soins destinés aux enfants.

Can. J. Neurol. Sci. 2001; 28: 319-321

As global health care costs rise and physician resources decrease, it is important to assess the costs and benefits of standard clinical care. In Nova Scotia, families have universal access to health care. As pediatric neurologists are paid by government and university through an alternate-funding program rather than on a fee-per-service basis, innovative approaches to service provision are encouraged.

Before introducing alternate methods of providing care, we undertook this pilot study of parents'attitudes to such care. The objectives of this pilot study were: 1) to study the views of families regarding the value of care delivered in a standard pediatric neurology clinic, 2) to assess the acceptability of potential alternate methods of care delivery and 3) to assess the impact on these views of multiple covariates, such as financial burden of the visit and satisfaction with the visit.

\begin{abstract}
METHODS
The study was carried out at the IWK Health Centre, Halifax, which is the only tertiary care pediatric center for the three Canadian Maritime provinces.

Questionnaires, designed to assess parents' perceptions of their visit to the clinic and the acceptability of alternate options, were given to 200 consecutive families on arrival at the clinic.

From the Department of Pediatrics, Division of Pediatric Neurology, Dalhousie University and the IWK Health Centre, Halifax, Nova Scotia, Canada. ReCEIVEd March 5, 2001. ACCEPTED InfinAlform May 28, 2001. Reprint requests to: J.M. Dooley, Neurology Division, IWK Health Centre, Halifax, Nova Scotia, Canada B3J 3G9
\end{abstract}


The first questionnaire was completed before the consultation and the second after their child was seen. Items covered in the questionnaires are outlined in the Table. In the second questionnaire, multiple aspects of the visit were assessed using the Visit Rating Questionnaire of the Medical Outcomes study. ${ }^{1}$ This questionnaire assessed the visit overall, the technical skills, personal manner and time spent with the physician and other aspects of the clinic experience. Families were asked to anonymously complete the questionnaires prior to leaving clinic.

Data were analyzed using Epi Info v 6.04 and Systat v 9.0. ${ }^{3}$

\section{RESULTS}

Responses to the first questionnaire were received from 172 families $(86 \%)$ and to the second from 138. As not all respondents replied to all questions, the numbers for individual questions were frequently less than the total.

The parents rated their child's health as very good or excellent for $78(46 \%)$, good for $68(40 \%)$ and fair or poor for $25(15 \%)$. The mean age of the patients was nine years (range four months to 23 years) while the mean parental age was 37 years (range 17 to 55 years). Personal educational achievement was reported by 164 parents, of whom $136(83 \%)$ had completed at least high school. Total median annual family income for the 146 responders was $\$ 35,000$.

There were 59 new referrals, 76 were seen in routine followup and 39 were seen in follow-up because of the occurrence of new concerns since the patient's last visit.

Attending clinic resulted in school absenteeism of less than half a day for $27(17 \%)$, half a day for $46(28 \%)$, a full day for $60(37 \%)$, more than one day for five (3\%) and was not applicable for $26(16 \%)$. Travelling to clinic also had an impact on parents. The median distance traveled was $54 \mathrm{~km}$ (75th percentile $125 \mathrm{~km}$ ) and $33(19 \%)$ of families lost pay because of work time missed to attend clinic. The financial cost was not a

\section{Table: Items covered in questionnaires}

\section{Before V isit Questionnaire}

Reason and need for visit

First or follow-up visit

Acceptability of visit with nurse, telephone or video conference

Time missed from school and work

Distance traveled, method of transport and driving conditions

Family income, cost of visit, loss of pay and if this was a concern

Child and parent's age and parent's education level

Parent's assessment of child's and own health

\author{
After Visit Questionnaire \\ Was visit helpful? \\ Assessment of multiple aspects of clinic visit ${ }^{1}$ \\ Acceptability of visit with nurse, telephone or video conference \\ Medication prescribed or tests performed \\ Need for follow-up and with whom
}

concern for 134 (79\%), just a little concerning for 25 (15\%) and pretty much or very much a concern for $11(6 \%)$. Concern about cost was not correlated with losing pay because of the visit. Most families $(128,74 \%)$ traveled to clinic in their own car. Although there was one snowstorm during the period of the study, only six (4\%) described driving conditions as difficult. The median reported expense incurred for attending clinic was $\$ 13.00$ (75th percentile $\$ 36.50$, range $\$ 0-\$ 260$ ).

The scheduled appointment was considered necessary by all but four (2\%), who were all seen for routine follow-up assessments. Only 14 of $168(8 \%)$ thought that the consultation could have been carried out by telephone, including one of 58 new referrals. Consultation through videoconference was acceptable for 15 of $165(9 \%)$ and six (4\%) families were either unsure or needed more information.

After the clinic visit 103 of 107 (96\%) thought the visit was helpful, while three (3\%) thought it was not and one $(1 \%)$ was unsure. Of the three families who did not think the visit was helpful, two rated "the visit overall" as very good and the other as excellent.

In the overall assessment of the clinic visit, 119 of $134(89 \%)$ thought their experience was very good or excellent. Of the remaining 15 families, $12(9 \%)$ thought it was good and three (2\%) thought it was fair. Nobody assessed it as poor.

Ratings of very good or excellent were received from $94 \%$ for technical skills of the physician and for the physician's personal manner and by $95 \%$ for the physician's explanation of what was done for their child. The delay to get an appointment was considered very good or excellent by $72 \%$. Ratings of very good or excellent were also received by $66 \%$ for convenience of clinic location and telephone access to the clinic, time spent in the waiting room by $61 \%$ and time spent with the physician by $87 \%$. In comparison to the findings of Rubin et al, ${ }^{1}$ our patients were less content with the office location $(p<0.0001)$ and accessibility by phone $(\mathrm{p}<0.0007)$ but were more satisfied with time spent with the physician $(\mathrm{p}<0.03)$ and the explanation provided by the physician $(\mathrm{p}<0.01)$.

Following the clinic visit 16 of $132(12 \%)$ thought that a nurse clinician could have replaced the physician at the appointment. Few thought that the visit could have been performed by telephone $(13 / 134,10 \%)$ or by video conferencing $(12 / 134,9 \%)$. Of 120 who initially did not think that telephone contact could have replaced the visit, seven changed their minds after the visit. In contrast, six of 12 who indicated that they would have preferred a telephone consultation prior to being seen changed their minds after the visit. Similarly, four of 115 who did not think video conferencing could replace the "in person" visit changed their opinions after being seen. Of the 12 who initially found video conferencing acceptable, four subsequently did not see this as an option. The only factor, which was associated with willingness to accept telephone as an assessment modality, was an initial opinion that the visit was unnecessary ( $p<0.001)$. Families who lived at a distance or were financially less able were not more likely to wish further contact by telephone or video. There was no correlation between willingness to accept telephone or video conference follow-up.

For follow-up, 71 of 129 (55\%) felt that either no follow-up was necessary or that they would contact the clinic in future if follow-up was required. If follow-up occurred, 74 of 79 (94\%) 
thought that it should occur with the pediatric neurologist and 71 (90\%) thought that it should occur in person rather than by telephone or video conference.

\section{Discussion}

The response rate of $86 \%$ indicates that this study is representative of the population served by our clinic. As the study was completed anonymously, we are unaware of the characteristics of the nonrespondents. It is possible that those who did not complete the second questionnaire were unhappy with the clinic experience, although anecdotal reports from a few parents indicated that their failure to comply was a reflection of their unwillingness to spend extra time at the hospital to complete the questionnaire.

Attending the clinic was associated with both school and work absenteeism and entailed travelling to the clinic. Although attending a clinic in Canada is not associated with direct costs, families reported that they spent about $\$ 13$ on travel-related expenses. Despite these factors, the vast majority of families felt the appointment was necessary and were very satisfied with the clinic experience. The ratings of the various aspects of the visit were very similar to those reported in the literature from a variety of different adult clinic settings. ${ }^{1}$ We received more excellent ratings for time spent with families and the explanation offered but less for office location and telephone access. Responses were not affected by distance traveled, parent age, level of education or income. Similarly the responses of those who were new referrals to the clinic were similar to those who were seen for routine or emergency follow-up assessments.

Further visits were thought necessary by half of the patients seen for follow-up compared to less than one third of new referrals. This discrepancy is not surprising, as many referrals to the clinic require a single assessment. The perceived need for follow-up was not correlated with distance traveled to clinic.

Very few felt that a nurse specialist could replace the pediatric neurologist in the clinic setting and $90 \%$ felt that follow-up by telephone or video conferencing was unacceptable. This may be due to unfamiliarity with alternate methods of delivering care, although many families use telephone contact with the clinic for advice between appointments. Telephone advice is an important aspect of clinical care and accounts for $28 \%$ of patient encounters with pediatricians. ${ }^{4}$ Such care, either by telephone or computerized communication, can result in greater continuity of care by enhancing patient access to physicians. ${ }^{5}$ Adult patients who were followed by telephone had fewer clinic visits, used less medication, had fewer admissions and shorter hospital stays than usual-care patients. ${ }^{6}$ In addition, the estimated total expenditures for telephone care were $28 \%$ less per patient for the two years of study. ${ }^{6}$ When exposed to follow-up by telephone $90 \%$ of a group of adult rheumatology patients were satisfied by the service, as were $94 \%$ of patients attending clinic. ${ }^{7}$ Other studies have also shown high patient satisfaction with the help received from doctors by telephone. ${ }^{8}$ Patient satisfaction was higher when breast biopsy results were given by telephone than when given in person. ${ }^{9}$ It is not clear if such satisfaction is applicable to the pediatric setting. Less than half of families who got after-hours telephone advice were compliant with the direction to take their child to the emergency department. ${ }^{10}$

In contrast, physician satisfaction with patient telephone demands is often low. ${ }^{11}$ Physicians assume moral and legal responsibility for telephone advice, although such advice is seldom compensated. There is, therefore, little incentive to offer telephone care as long as physicians continue to work on a feefor-service basis. The American Society of Internal Medicine has suggested payment for telephone calls that involve evaluation of a new problem and a medical decision, that prevent an office or emergency room visit and that involve the physician personally. ${ }^{12}$ As all physicians must offer telecommunications care, appropriate training should be offered during residency. ${ }^{13}$ Reserving time for such calls by increasing periods of availability and publicizing availability can enhance the use of telephone contact with physicians. ${ }^{14}$

In conclusion, parents are reticent to accept follow-up care for their children either by telephone or video conference, despite a high level of satisfaction with such care in the literature. The reluctance expressed by our families may reflect their lack of familiarity with new technology. It is possible that they would find such care acceptable if offered, despite these preconceived attitudes. Our results, however, demand caution in the introduction of alternate methods of delivering care.

\section{REFERENCES}

1. Rubin HR, Gandek B, Rogers WH, et al. Patients' ratings of outpatient visits in different practice setting. JAMA 1993;270: 835-840.

2. Dean AD, Dean JA, Burton AH, Dicker RC. Epi Info version 6.04: A Word Processing, Database and Statistics Program for Epidemiology on Microcomputers. Stone Mountain, Ga: USD Inc. 1990.

3. Systat Version 7.0. (1997) SSPS Inc. Chicago, Il 60611.

4. Sorum PC. Compensating physicians for telephone calls. JAMA 1994; 272: 1949-1950.

5. Balas EA, Jaffrey F, Kuperman GJ, et al. Electronic communication with patients: evaluation of distance medicine technology. JAMA 1997;278:152-159.

6. Wasson J, Gaudette C, Whaley F, et al. Telephone care as a substitute for routine clinic follow-up. JAMA 1992;267:17881793.

7. Pal B. Following up outpatients by telephone: pilot study. Br Med J 1998;316:1647.

8. Hallam L. Access to general practice and general practitioners by telephone: the patient's view. Br J Gen Pract 1993;43:331-335.

9. Campbell L, Watkins RM, Teasdale C. Communicating the result of breast biopsy by telephone or in person. Br J Surg 1997;84:1381.

10. Baker RC, Schubert CJ, Kirwan KA, Lenkauskas SM, Spaeth JT. After-hours telephone triage and advice in private and nonprivate pediatric patients. Arch Pediatr Adolesc Med 1999;153:292-296.

11. Fosarelli P, Schmitt B. Telephone dissatisfaction in pediatric practice: Denver and Baltimore. Pediatrics 1987;80:28-31.

12. American Society of Internal Medicine. Telephone care by your doctor. Internist 1992;33:37.

13. Zylke JW. Physicians need better line on how, when to respond to patients via telephone. JAMA1990;264:1797-1798.

14. Hallam L. Organisation of telephone services and patients'access to doctors by telephone in general practice. Br Med J 1991;302:629632 . 